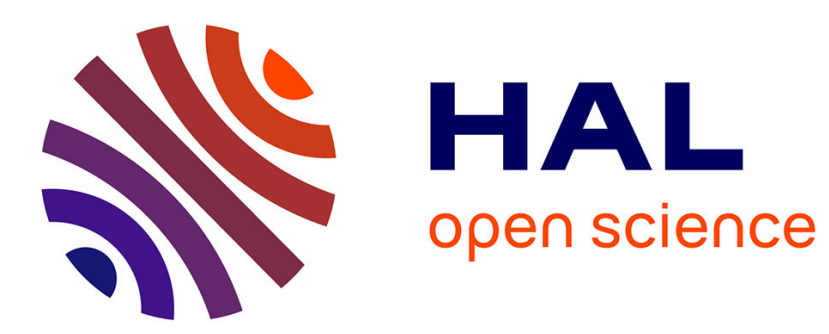

\title{
Internal Friction in Cu-Al-Ni Crystals in Martensitic Phase and During Temperature-Induced Martensitic Transformation
}

\author{
S. Kustov, S. Golyandin, I. Hurtado, J. van Humbeeck, R. de Batist
}

\section{- To cite this version:}

S. Kustov, S. Golyandin, I. Hurtado, J. van Humbeeck, R. de Batist. Internal Friction in Cu-Al-Ni Crystals in Martensitic Phase and During Temperature-Induced Martensitic Transformation. Journal de Physique IV Proceedings, 1996, 06 (C8), pp.C8-389-C8-392. 10.1051/jp4:1996883 . jpa-00254694

\author{
HAL Id: jpa-00254694 \\ https://hal.science/jpa-00254694
}

Submitted on 1 Jan 1996

HAL is a multi-disciplinary open access archive for the deposit and dissemination of scientific research documents, whether they are published or not. The documents may come from teaching and research institutions in France or abroad, or from public or private research centers.
L'archive ouverte pluridisciplinaire HAL, est destinée au dépôt et à la diffusion de documents scientifiques de niveau recherche, publiés ou non, émanant des établissements d'enseignement et de recherche français ou étrangers, des laboratoires publics ou privés. 


\title{
Internal Friction in Cu-Al-Ni Crystals in Martensitic Phase and During Temperature-Induced Martensitic Transformation
}

\author{
S.B. Kustov, S.N. Golyandin, I. Hurtado*, J. Van Humbeeck* and R. de Batist** \\ A.F. Ioffe Physical-Technical Institute, Russian Academy of Sciences, Politekhnicheskaya 26, \\ St. Petersburg 194021, Russia \\ * Department MTM, Katholieke Universiteit Leuven, De Croylaan 2, 3001 Heverlee, Belgium \\ ** Institute of Material Science, University of Antwerpen (RUCA), Middelheimlaan 1, 2020 Antwerp, \\ Belgium
}

\begin{abstract}
Temperature and oscillatory strain amplitude dependences of the ultrasonic amplitude-dependent internal friction and oscillatory anelastic strain at temperatures $6.5-300 \mathrm{~K}$ have been studied in Cu-Al-Ni single crystals in martensitic phase. An anomalous behaviour of the amplitude dependent internal friction and effective Young modulus was revealed in quenched crystals: the amplitude dependent internal friction decreases with temperature increase at all temperatures and strain amplitudes investigated, and the Young modulus increases notably with temperature from 70 to $200 \mathrm{~K}$. The anomalies in the ADIF and effective Young modulus behaviour are attributed to peculiarities of dislocation dynamics.
\end{abstract}

\section{INTRODUCTION}

Recently detailed investigations of the amplitude dependent internal friction (ADIF) were performed during temperature or stress induced thermoelastic martensitic transformation and in the martensitic phase of $\mathrm{Cu}$ Al-Ni single crystals [1-4]. Application of the ultrasonic technique allowed to avoid the influence of the transient internal friction component during phase transformation and to investigate the "structural" IF component, independent on heating-cooling rate and less dependent on frequency. The conclusion has been drawn in $[1,2]$ that the structural ADIF at ultrasonic frequencies represents a pronounced premartensitic component which might be attributed to the nucleation of martensite on dislocations.

"Dislocation" rather than "interface" nature of the intrinsic ADIF in martensitic phase was suggested in $[3,4]$. Contrary to the conclusion based on data of positron annihilation studies [5], defects, related to quenchedin vacancies were found to be highly mobile in $\beta_{1}^{\prime}$ martensitic phase of $\mathrm{Cu}-\mathrm{Al}-\mathrm{Ni}$ crystals. Moreover, the conclusion was drawn that these mobile point obstacles determine the main peculiarities of the amplitudefrequency spectra of the quenched $\mathrm{Cu}-\mathrm{Al}-\mathrm{Ni}$ crystals, revealed by different techniques in the range from infrato ultrasonic frequencies.

The present paper reports the results of ultrasonic studies of details of dislocation-mobile pinning obstacle (PO) interaction in $\beta_{1}^{\prime}$ martensitic phase of quenched $\mathrm{Cu}-\mathrm{Al}-\mathrm{Ni}$ crystals at temperatures $6.5-300 \mathrm{~K}$.

\section{EXPERIMENTAL DETAILS}

Amplitude and temperature dependences of the internal friction, Young modulus and Young modulus defect were measured at a frequency of about $100 \mathrm{kHz}$ by means of a computer-controlled setup based on resonant three-component piezoelectric oscillator technique. During the experimental procedure samples were cooled/heated at a rate of approx. $1 \mathrm{~K} / \mathrm{min}$ in a liquid helium cryostat. Temperature dependences of the decrement and resonant frequency were measured at two oscillatory strain amplitudes, $10^{-6}$ and $3 * 10^{-5}$, in one temperature run. The sample was kept continuously oscillating at the lower strain amplitude, and was excited to strain amplitude $3.0^{*} 10^{-5}$ for a short time to take a data point. Amplitude dependences of the $\mathrm{ADIF}$ and resonant frequency were taken during such temperature run at $\sim 20 \mathrm{~K}$ intervals and consisted of the strain amplitude increase (direct) and strain amplitude decrease (reverse) runs. The maximum strain amplitude during the amplitude dependence measurement was $1-2 * 10^{-4}$. Single crystals of Cu- 
13.2wt\%Al-4.0wt\% $\mathrm{Ni}$ alloy $\left(\mathrm{M}_{\mathrm{s}}\right.$ temperature $\left.370 \mathrm{~K}\right)$ had a [100] $\beta$-phase orientation and dimensions approx. $1.5^{*} 1.5^{*} 15 \mathrm{~mm}$. After quenching into water from $900^{\circ} \mathrm{C}$ the samples had $\beta_{1}{ }^{\prime}$ martensite structure.

\section{RESULTS AND DISCUSSION}

Figure 1 shows temperature dependences of the decrement (a) and the effective Young modulus (b) of a quenched sample on cooling and subsequent heating. The evolution of strain amplitude dependences of the $\mathrm{ADIF}$ with temperature during heating is represented in fig. 2. At the lowest temperatures (below 70K) the ADIF is essentially temperature independent. At these temperatures no amplitude hysteresis can be resolved in the amplitude dependence of the decrement. Above $\sim 90 \mathrm{~K}$, the $\mathrm{ADIF}$ decreases with increasing temperature, simultaneously with the appearance and the increase of the ADIF amplitude hysteresis (fig.2). The fastest decrease of the ADIF is revealed at $170-230 \mathrm{~K}$, when instabilities in the decrement occur in the amplitude-dependent range, figs. 1, 2. At temperatures higher than $230 \mathrm{~K}$ strain amplitude $3 * 10^{-5}$ falls within the amplitudeindependent range (fig. 1(a)).

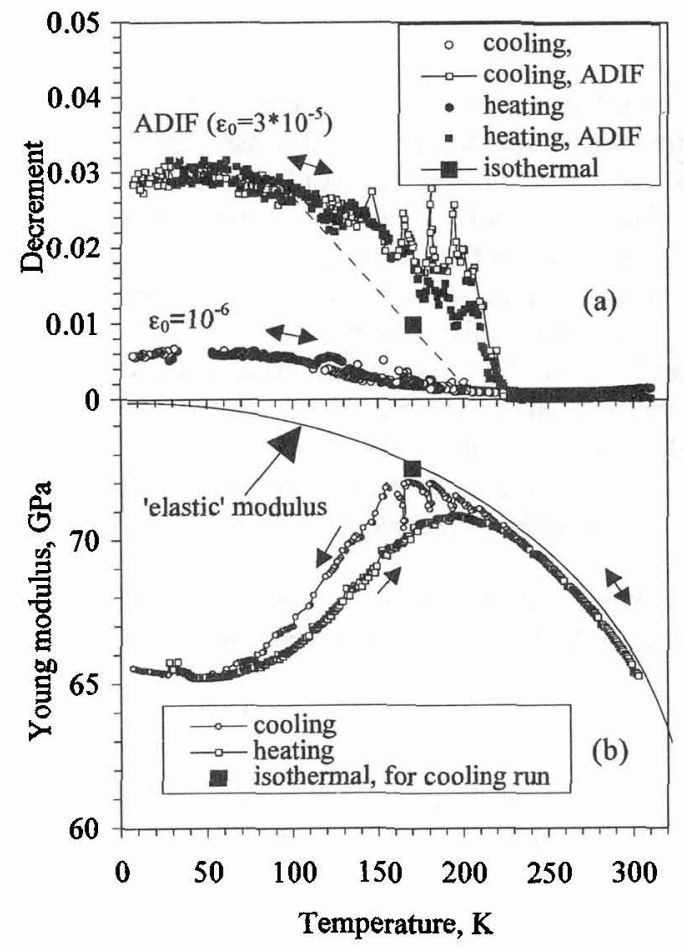

Figure 1: Temperature dependences of the decrement (a) and effective Young modulus (b) measured for the elastic strain amplitude $\varepsilon_{0}=10^{-6}$ on heating and cooling of a quenched sample. In fig. 1(a) the amplitude dependent difference between the decrement at strain amplitudes $3 * 10^{-5}$ and $10^{-6}$ is shown as well.

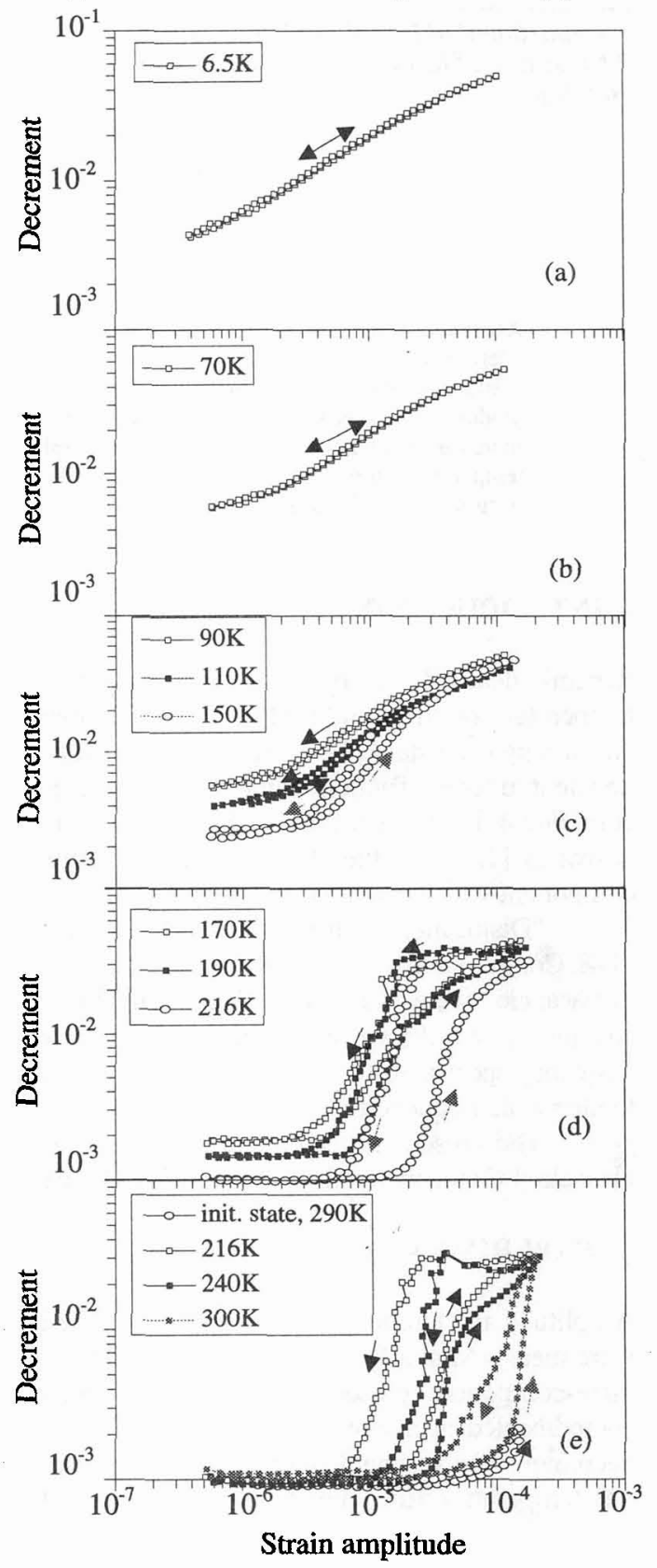

Figure 2: Strain amplitude dependences of the decrement taken during heating of a quenched sample. 
An anomalous decrease of the effective Young modulus with decreasing temperature occurs at 200-70K. This temperature range coincides fairly well with the drastic increase of the ADIF. Therefore, this anomaly is most likely due to a contribution of anelastic dislocation strain even at rather low oscillatory strain amplitude.

The above mentioned observations can be explained fairly consistent by the existence of pinning PO atmospheres, mobile above $\sim 90 \mathrm{~K}$. An essential requirement for this explanation consists in the presence of thermal stresses induced within variants during cooling/heating of sample due to the high anisotropy of the elastic properties of martensite variants. Indeed, in the initial state at room temperature the ADIF of the sample is rather low due to the existence of dense atmospheres of PO (fig. 2(e)). During cooling PO become less mobile and partial dislocations can escape from these atmospheres under the action of the biasing thermal stress. This process is enhanced by high-amplitude ultrasonic oscillations. The additional influence of the ultrasonic oscillations on the depinning under the action of thermal stress on cooling is clearly indicated at $230-150 \mathrm{~K}$ by the additional decrement increase and Young modulus decrease, initiated by the ADIF measurements, fig. 1(a),(b).

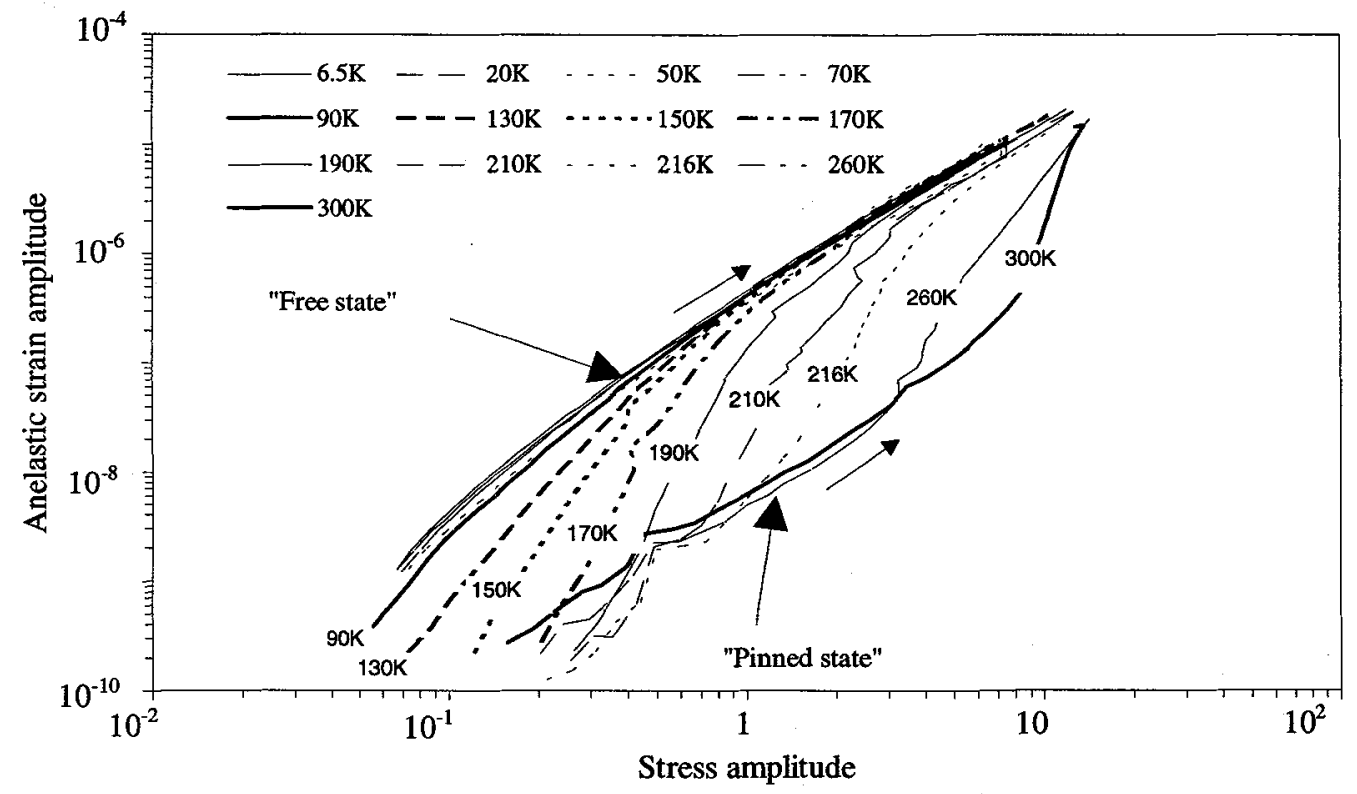

Figure 3: Stress amplitude dependences of the anelastic strain amplitude for a quenched sample, corresponding to the increasing stress amplitude runs, measured during heating.

Considering a network of partial dislocations as the basic contributor to the ADIF at ultrasonic frequencies, one can conclude, that below $\sim 70 \mathrm{~K}$ the dislocation network is free of pinning atmospheres, which cease to be mobile. As for a specific model which can account for the temperature independent ADIF below $\sim 70 \mathrm{~K}$ we remark here that the internal friction in this temperature range is rather weakly amplitude dependent. In addition, the amplitude independent range is not attained even at the lowest strain amplitudes investigated $\left(3 * 10^{-7}\right.$, see fig. 2(a)). These regularities correspond with the hysteretic background model, proposed in [6]. From this standpoint, the hysteretic internal friction below $70 \mathrm{~K}$ is due to the oscillations of free partials in stress fields of weak but long range PO, distributed in the bulk. Another agreement of our data with the model [6] consists in a very high values of the modulus defect at low strain amplitudes, compared to the background internal friction. The estimated behaviour of the 'elastic' modulus (disregarding dislocation contribution) is shown schematically in fig. 1(b).

On heating, the ADIF starts to decrease with the appearance of the ADIF hysteresis. Apparently, PO become sufficiently mobile to diffuse to dislocations. This causes the drastic increase of the modulus, fig. 1(b), since the partials collect more and stronger pinning points. This explains also the decrease of the decrement at the lowest strain amplitudes. With further temperature increase the ADIF continues to decrease at the lowest strain amplitudes and becomes suppressed in a larger strain amplitude range, indicating the increase both of the density and size of the PO atmospheres. At high strain amplitude the internal friction amplitude dependence approaches the low-temperature level and slope, fig. 2(c),(d),(e). In the temperature range, where amplitude 
hysteresis is observed, the ADIF appears to be $\dot{T}$ dependent. It is indicated by the isothermal point in the ADIF and effective modulus, fig. 1. On the other hand, diffusion related processes, influencing the ADIF should lead to amplitude dependent relaxation at low frequencies [7].

The anelastic strain amplitude, $\varepsilon_{\text {an, }}$, which can be derived from the Young modulus defect values, $(\Delta \mathrm{E} / \mathrm{E})_{\mathrm{h}}$, provides more direct evidence of the type of dislocation motion than the ADIF. Fig. 3 depicts the anelastic strain amplitude $\varepsilon_{\mathrm{an}}=(\Delta \mathrm{E} / \mathrm{E})_{\mathrm{h}} \varepsilon_{0}$, where $\varepsilon_{0}$ is the strain amplitude, derived from the direct runs of the $(\Delta \mathrm{E} / \mathrm{E})_{\mathrm{h}}$ stress amplitude dependences, measured at different temperatures during heating. Clearly, the behaviour of the anelastic strain amplitude dependences may be considered as a transition from the completely pinned to the completely free state. This transition implies a breakthrough of the dislocations through pinning atmospheres and is observable at moderate temperatures (below approx. 220K for the heating rate and stress amplitudes used in present experiment). At higher temperatures the atmospheres become more dense and more mobile. Therefore attaining the "free state" is inhibited for the strain amplitude used, see curves for 260 and $300 \mathrm{~K}$. We notice here, that the anelastic strain behaviour in the "free state" is essentially temperature independent and practically coincides in the whole temperature range investigated with that, observed at $6.5 \mathrm{~K}$. Thus, the behaviour of dislocations in the "free state" corresponds mainly to athermal hysteretic ADIF mechanism. One cannot exclude, however, a minor effect of temperature which might lead to the increase of the ADIF in the "free state".

The transition from the "pinned state" to the "free state", when the atmospheres are rather developed (i.e. PO are rather mobile), is accompanied by instabilities of the decrement (see curves in fig. 1 in the range 190$240 \mathrm{~K}$ ). We emphasise here, that those instabilities appear in the presence of thermal stresses, which displace dislocations far enough from the pinning atmosphere, causing rapid change of the ADIF. Unpinned dislocations, on the other hand, are rapidly trapped by mobile PO, thus causing a kind of "jerky" behaviour of the ADIF.

\section{CONCLUSIONS}

Pronounced anomalies in the ADIF and effective Young modulus are revealed in a martensitic polyvariant $\mathrm{Cu}-\mathrm{Al}$ $\mathrm{Ni}$ single crystals in temperature range $70-200 \mathrm{~K}$ and are attributed to a change of the state of dislocations from essentially free (low temperatures) to strongly pinned (ambient temperature). Under combined action of static thermal and ultrasonic oscillatory stresses unpinning of dislocations is accompanied by instabilities of the ADIF.

Only one stage of dislocation pinning is resolved in quenched crystals between $6.5-300 \mathrm{~K}$. PO, responsible for the pinning of dislocations are mobile at temperatures higher than $\sim 70 \mathrm{~K}$. Although being highly mobile at room temperature, they are not annealed in martensitic phase.

The highest ADIF and anelastic strain is observed at the lowest temperatures and is attributed to mainly hysteretic temperature independent motion of a network of partial dislocations in the stress fields of weak long range obstacles. At low temperatures and at low strain amplitudes, the anelastic contribution of dislocations to the measured Young's modulus is found to be very large.

\section{Acknowledgements}

S. Kustov and S. Golyandin acknowledge Russian Foundation for Basic Research for a partial financial support (grant 96-01-01207a).

\section{References}

[1] Kustov S., Van Humbeeck J., De Batist R., Scripta Materialia, 33 (1995) 1401-1407.

[2] Sapozhnikov K.V., Vetrov V.V..,Pulnev S.A., and Kùstơv S.B., Scripta Materialia, 34 (1996) 1543-1548.

[3] Kustov S.B., Golyandin S.N., Hurtado I., Van Humbeeck J. and De Batist R., J. De Phys.IV, 5 Coll. C8 (1995) C8-943-C8-948.

[4] Kustov S.B., Van Humbeeck J., Hurtado I., Golyandin S. and De Batist R., Proceedings of the International Symposium "M3D3", Norfolk, USA, November, 1995, ASTM STP N 1304, in print.

[5] Kong Y., Jiang B., Hsu T.J., Wang B., Wang T., Mat. Res. Soc. Symp. Proc. 246 (1992) 25-30.

[6] Gremaud G., J. de Phys. 48 Coll. C8 (1987) C8-15-C8-30.

[7] Kustov S., Golyandin S., Van Humbeeck J., De Batist R., this conference. 